\title{
Urban flood risk assessment: integration of decision making
}

\section{and machine learning}

\author{
Fereshteh Taromideh ${ }^{1}$, Ramin Fazloula ${ }^{1, *}$, Bahram Choubin ${ }^{2}$, Alireza Emadi ${ }^{1}$ and Ronny Berndtsson ${ }^{3, *}$ \\ 1 Department of Water Engineering, Sari Agricultural Sciences and Natural Resources University, Sari, Iran; \\ f.taromide@stu.sanru.ac.ir; r.fazloula@sanru.ac.ir; a.emadi@sanru.ac.ir \\ 2 Soil Conservation and Watershed Management Research Department, West Azarbaijan Agricultural and \\ Natural Resources Research and Education Center, AREEO, Urmia, Iran; b.choubin@areeo.ac.ir \\ 3 Centre for Advanced Middle Eastern Studies \& Division of Water Resources Engineering, Lund University, \\ Box 118, SE-221 00 Lund, Sweden; ronny.berndtsson@tvrl.lth.se \\ * Correspondence: r.fazloula@sanru.ac.ir; ronny.berndtsson@tvrl.1th.se
}

\begin{abstract}
Urban flood risk mapping is an important tool for the mitigation of flooding in view of human activities and climate change. Many developing countries, however, lack sufficiently detailed data to produce reliable risk maps with existing methods. Thus, improved methods are needed that can improve urban flood risk management in regions with scarce hydrological data. Given this, we estimated the flood risk map for Rasht City (Iran), applying a composition of decision-making and machine learning methods. Flood hazard maps were produced applying six stateof-the-art machine learning methods such as classification and regression trees (CART), random forest (RF), boosted regression trees (BRT), multivariate adaptive regression splines (MARS), multivariate discriminant analysis (MDA), and support vector machine (SVM). Flood conditioning parameters applied in modeling were elevation, slope angle, aspect, rainfall, distance to river (DTR), distance to streets (DTS), soil hydrological group (SHG), curve number $(\mathrm{CN})$, distance to urban drainage (DTUD), urban drainage density (UDD), and land use. In total, 93 flood location points were collected from the regional water company of Gilan province combined with field surveys. We used the Analytic Hierarchy Process (AHP) decision-making tool for creating an urban flood vulnerability map, which is according to population density (PD), dwelling quality (DQ), household income $(\mathrm{HI})$, distance to cultural heritage $(\mathrm{DTCH})$, distance to medical centers and hospitals (DTMCH), and land use. Then, the urban flood risk map was derived according to flood vulnerability and flood hazard maps. Evaluation of models was performed using receiver-operator characteristic curve (ROC), accuracy, probability of detection (POD), false alarm ratio (FAR), and precision. The findings showed that the CART method is most accurate method (AUC $=0.947$, accuracy $=$ $0.892, \mathrm{POD}=0.867, \mathrm{FAR}=0.071$, and precision $=0.929$ ). The results also demonstrated that DTR, UDD, and DTUD played important roles in flood hazard modeling; whereas, the population density was the most significant parameter in vulnerability mapping. These findings indicated that machine learning methods can improve urban flood risk management significantly in regions with limited hydrological data.
\end{abstract}

Keywords: Urban flood; Decision making; Machine learning; Risk; Hazard; Vulnerability

\section{Introduction}

Between natural disasters, flooding is one of the most destructive hazards causing severe economic damage. Climate change is expected to increase the severity of flooding in many parts of the world $[1,2]$. Population growth, industrial expansion, lack of space for construction, especially in metropolitan areas, have caused drastic changes in the morphology of urban watersheds. This has increased the flooding in urban areas and risks for losses of human lives and property. From 1998 to 2017, more than 2 billion people were affected by flooding throughout the world [3]. Also, Iran has been severely affected by 
flooding during recent years [4]. For instance, in March 2019, at least 28 out of 31 provinces of Iran were affected by three major floods for two weeks causing infrastructure destruction of more than $\$ 3.5$ billion $[5,6]$. Due to the high destructive impacts of floods, there is a great need for improved flood risk mapping. However, the scarcity of available hydrological and land use data causes difficulties in managing the flooding $[7,8]$.

Common practices to evaluate urban flood risk involve hydrological and hydraulic parameterization methods to approximate flow and water levels at observation stations $[9,10,11,12]$. Lacking rainfall and runoff data increases uncertainties and errors of these estimates [9]. Also, recent studies have shown that the flood risk assessment requires more than an assessment of hydrological processes. A reason for this is that urban areas are not homogeneous in terms of socioeconomic conditions [13, 9, 12]. Thus, the adverse effects of floods likely affect the socially vulnerable part of the urban population more severely [14]. An indirect method is to employ multi-criteria decision-making methods (MCDM) for addressing this $[15,16]$. Analytic Hierarchy Process (AHP) is an MCDM method that has recently been employed in flood studies [17, 18]. The MCDM methods include both subjective and objective assessments into an integrated structure according to scales with uniform comparisons that help to organize the necessary aspects of a problem into a framework. The advantages of this approach involve measuring the consistency of decision makers' judgments, generating pairwise comparisons for choosing a solution, and the ability to consider criteria and sub-criteria to evaluate options [15, 17].

Moreover, the MCDM methods, machine learning (ML) can be used to assess risks that are not exclusively caused by hydraulic factors [19, 20]. Accordingly, recent studies have been used machine learning approaches to estimate flood hazards such as classification and regression trees (CART) [21], random forest (RF) [22], boosted regression trees (BRT) [23], multivariate adaptive regression splines (MARS) [24, 25], multivariate discriminant analysis (MDA) [26], and also support vector machine (SVM) [27, 28, 22]. Due to the complexity of flood risk assessment, some advantages of the ML models have been reported in this regard. For example, the CART model has been shown to perform well for significant internal heterogeneity and nonlinear structures and this method can easily handle outliers $[29,30]$. The RF method determines the outcome according to predictions of the decision trees by taking the mean or average of the output from various trees [31, 32,33 . The BRT method can apply various variables and handle different predictor variables [34,35]. The MARS method is more flexible than linear regression models, and it is simple to understand and interpret [24]. The MDA derives a linear combination of several variables that are best at differentiating between pre-determined independent categories [26]. The advantages of SVM are (i) effective in cases where the number of dimensions is greater than the number of samples, (ii) effective in high dimensional spaces, and (iii) memory-efficient because it uses a subset of training points in the decision function (named support vectors) [36].

The objective of this study was not only to assess flooding due to hydrology and hydraulic factors but also to identify the most vulnerable areas to flood. Since risk is a function of hazard and vulnerability [37], integration of success methods (such as decision making and machine learning) for assessing both of them has not been well-documented yet; thus, this is the main objective of the research. Therefore, the specific objectives were to (i) compare machine learningmodels of CART, RF, BRT, MDA, MARS, and SVM to create urban flood hazard maps and recognize hazardous regions, (ii) recognize the most significant flood conditioning indicators, (iii) creation of urban flood vulnerability with a decision-making method, and (iv) combine decision-making with machine learning methods for creating urban flood risk maps. 


\section{Materials and Methods}

\subsection{Study area}

Rasht is one of the largest cities in Gilan Province in northern Iran. It has an area of about $95 \mathrm{~km} 2$ and is located between longitudes of $49^{\circ} 27^{\prime} 42^{\prime \prime}$ and $49^{\circ} 55^{\prime} 18^{\prime \prime}$ east and latitudes of $37^{\circ} 00^{\prime} 30^{\prime \prime}$ and $37^{\circ} 27^{\prime} 20^{\prime \prime}$ north (Figure 1 ). The elevation varies between $14 \mathrm{~m}$ to $255 \mathrm{~m}$ above average sea level. Rasht is the largest city on the southern Iranian coast of the Caspian Sea, with a population of about 631,951 [38]. The region has a Mediterranean climate, and the average annual precipitation and temperature are about $1337 \mathrm{~mm}$ and $10^{\circ} \mathrm{C}$, respectively, from 2000 to 2019. The Gohar and Zarjoub Rivers pass through the south of Rasht and then discharge into the Anzali Lagoon [39]. Due to the climatic conditions with heavy and sudden rainfall, passing two rivers from the area, the city is exposed to frequent and severe flash floods because of lack of proper drainage system, lack of flood warning system, and deforestation [40]. For instance, the destructive floods that occurred in 2019/03/25 and 2019/04/02 (with peak flows of $132 \mathrm{m3} / \mathrm{s}$ and $169.4 \mathrm{~m} 3 / \mathrm{s}$, respectively), caused widespread damage to infrastructure, bridges, roads, and temporary homelessness [6]; (Figure 2).
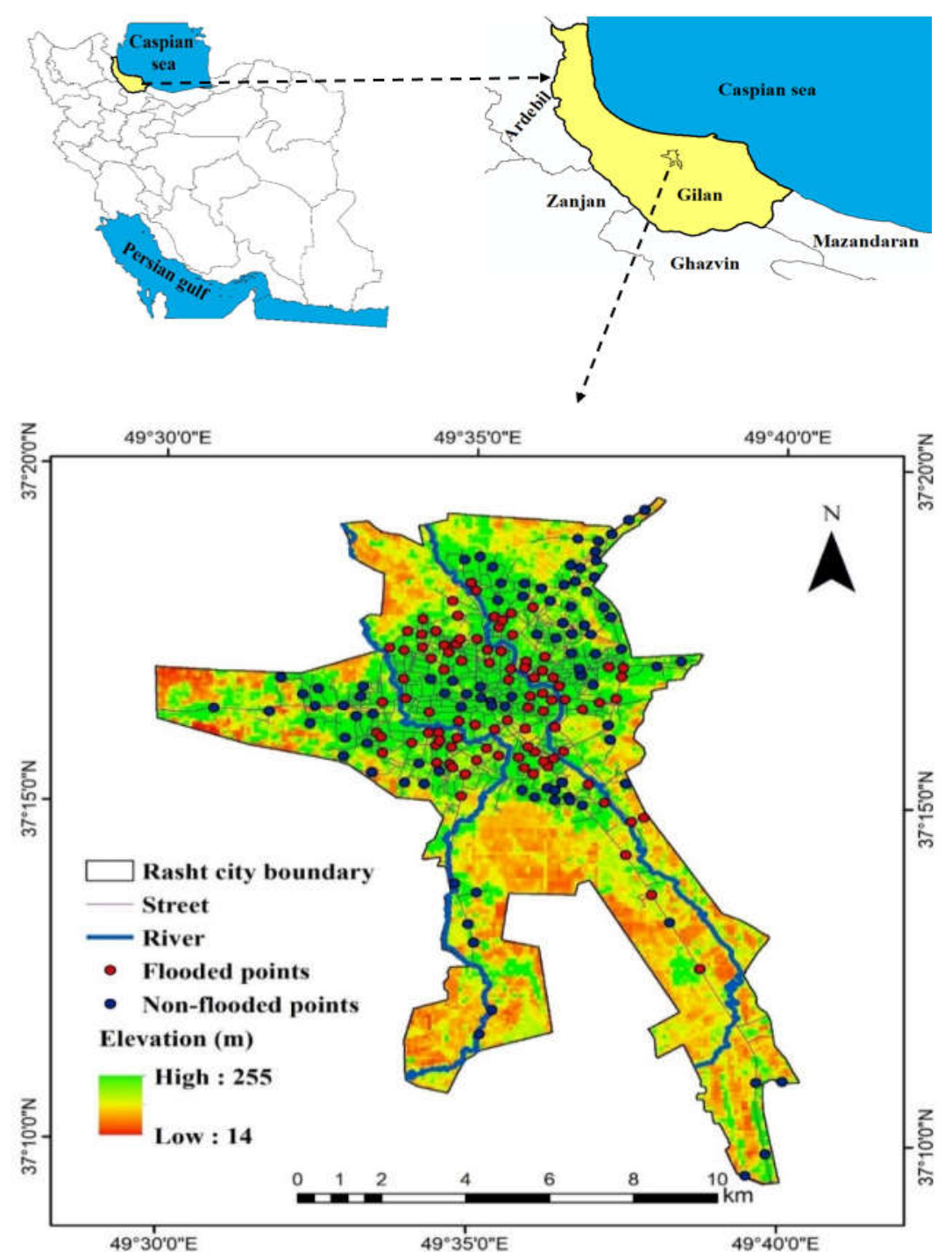

Figure 1. Location of Rasht City in Iran. 

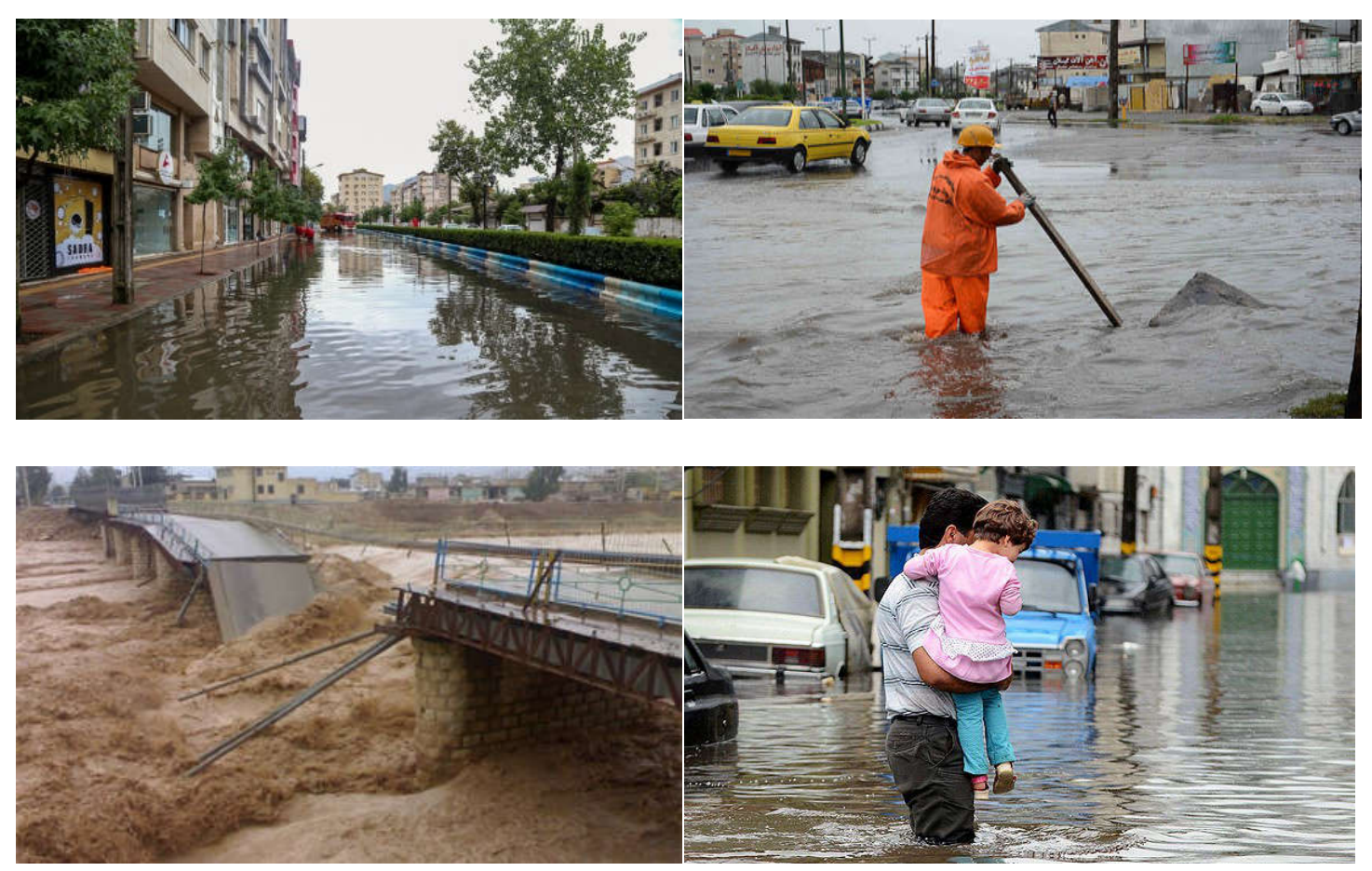

Figure 2. Examples of inundation problems during the flood occurred in 2019 in Rasht City. The photographs were taken by Fereshteh Taromideh in 2019.2.2. Urban flood inventory map

In total, 93 flood location points, recognized between the years 2009 to 2020, were collected from the regional water company of Gilan Province and field surveys. In addition, the equal number of flooded locations (i.e., 93 points) was randomly considered as non-flooded points (by using the random tool in ArcGIS 10.7; Figure 1). The location of flooded sites indicates that the important areas of the city such as residential regions, natural ecosystems, transportation systems, etc, have been exposed to floods.

\subsection{Urban flood vulnerability evaluation}

Vulnerability shows the degree of a system is incapable to handle or susceptible to the destructive influence of high flows or water levels. Consequently, vulnerability shows the society's sensitivity to flooding phenomena with environmental, social, and economic sustainability components [41]. We used the population density (PD), dwelling quality (DQ), household income (HI), distance to cultural heritage (DTCH), distance to medical centers and hospitals (DTMCH), and land use for vulnerability assessment of urban flood (Table 1 and Figure 3a to 3f). A questionnaire based on the analytical hierarchy process (AHP) method was prepared to evaluate the urban flood vulnerability based on expert knowledge. The AHP method applies a hierarchical structure to indicate a problem together with a user judgment to develop priorities for alternatives [42]. This method is conducted in five steps [43](Yalcin, 2008): (i) division of the problem into component parameters, (ii) development of the hierarchy, (iii) development of a paired comparison matrix according to the subjective judgment as described by Bidwai et al. [44], (IV) estimating the relative weights of factors, and (V) assess inconsistency of subjective judgment. For more details on AHP, see Bidwai et al. [44] and Danumah et al. [18]. All 
allocated scores by expert society according to Saaty scale [42] were checked using inconsistency ratios. If the inconsistency ratio was less than 0.1 , we used subjective judgment with SuperDecision and AHP method $[44,18]$.

After computing the weights of layers using the AHP model, the pixel values of every layer were normalized according to the membership functions (MF). Then the flood vulnerability map (FV) was produced using the raster calculator tools in the ArcGIS 10.7as follows:

$$
F V=\frac{\sum_{i=1}^{i=n} W_{i} \times N_{i}}{\sum_{i=1}^{i=n} W_{i}},
$$

where FV is flood vulnerability, $W_{i}$ is the weight of variable $i$ calculated by the AHP model, $N_{i}$ is the normalized layer of variable $i$, and $n$ is the number of variables.

The data for vulnerability factors were taken from the National Statistics Center of Iran, Gilan Road, and Urban Development Office, Management and Planning Organization of Gilan, and Rasht City Authority for 2016.

Population density (PD) indicates the number of people who are living in each urban area. Vulnerability is higher in high PD regions (Figure 3a). The data for the population density factor was taken from Rasht City Authority for 2016, with a pixel size of $12 \times 12 \mathrm{~m}$. The PD was placed into five groups: very high, high, moderate, low, and very low densities, which the very high category shows the range of 200-250 people in hectare. The classification of all six factors was carried out by Rash City Authority. Dwelling quality (DQ) shows building conditions that as well were divided into five groups: very high, high, moderate, low, and very low qualities. The data for the DQ factor was taken from Gilan Road and Urban Development Office for 2019. When flooding occurs, higherquality buildings are more resistant to damage. Household income (HI) is defined as the financial status of people, which is the combined income of all members of a household above a specific age (older than 18). Floods tend to influence all income classes in a region, but it is supposed that households with more finance need a shorter recovery time after the disaster. Generally, areas with a higher level of income are less exposed to damage by floods than areas with a poorer level of income [45, 46]. HI, as well, was divided into five groups (very good, good, moderate, poor, and very poor) based on information from Ministry of Cooperatives, Labour and Social Welfare in 2019. Distance to cultural heritage (DTCH) was determined according to Figure $3 \mathrm{~d}$ where most of the cultural heritage is located in the center of the city. When DTCH decreases, vulnerability increases. Distance to medical centers and hospitals (DTMCH) is another factor. An increase in DTMCH has a direct relationship with vulnerability. Euclidean distance tool in ArcGIS 10.7 was applied for preparing maps of DTCH and DTHMC. Both DTCH and DTHMC were taken from Rasht City Authority. Land use is another important indicator for flood vulnerability evaluation. Each land use has different reaction to flooding. Because of different landuses, runoff extremely varies, and runoff condition affect the vulnerability considerably [17, 6]. The land use map was obtained from Rasht City Authority in 2019. The land use map of the study area was divided into seventeen categories (road and street, agriculture, office, educational, religious, commercial-service, urban facilities and equipment, sports venues, barren land, waterbody, tourist places, medical services, green space, cultural heritage, 
animal husbandry, industrial areas, and residential area). The residential and agricultural areas are about $34 \%$ and $25 \%$ of the area respectively, and other land uses include about $41 \%$ of the area.

Table 1. Vulnerability factors.

\begin{tabular}{ccc}
\hline Factor & Type & Relationship with vulnerability \\
\hline Population density (PD) & Social & Higher number of people, higher vulnerability \\
\hline Land use & Physical & Based on expert knowledge \\
\hline Dwelling quality (DQ) & Economic & Higher dwelling quality, lower vulnerability \\
\hline Household income (HI) & Economic & Higher income, lower vulnerability \\
\hline Distance to cultural heritage (DTCH) & Social & Higher DTCH, lower vulnerability \\
\hline Distance to medical centers and hospitals (DTMCH) & Social & Higher DTMCH, higher vulnerability \\
\hline
\end{tabular}
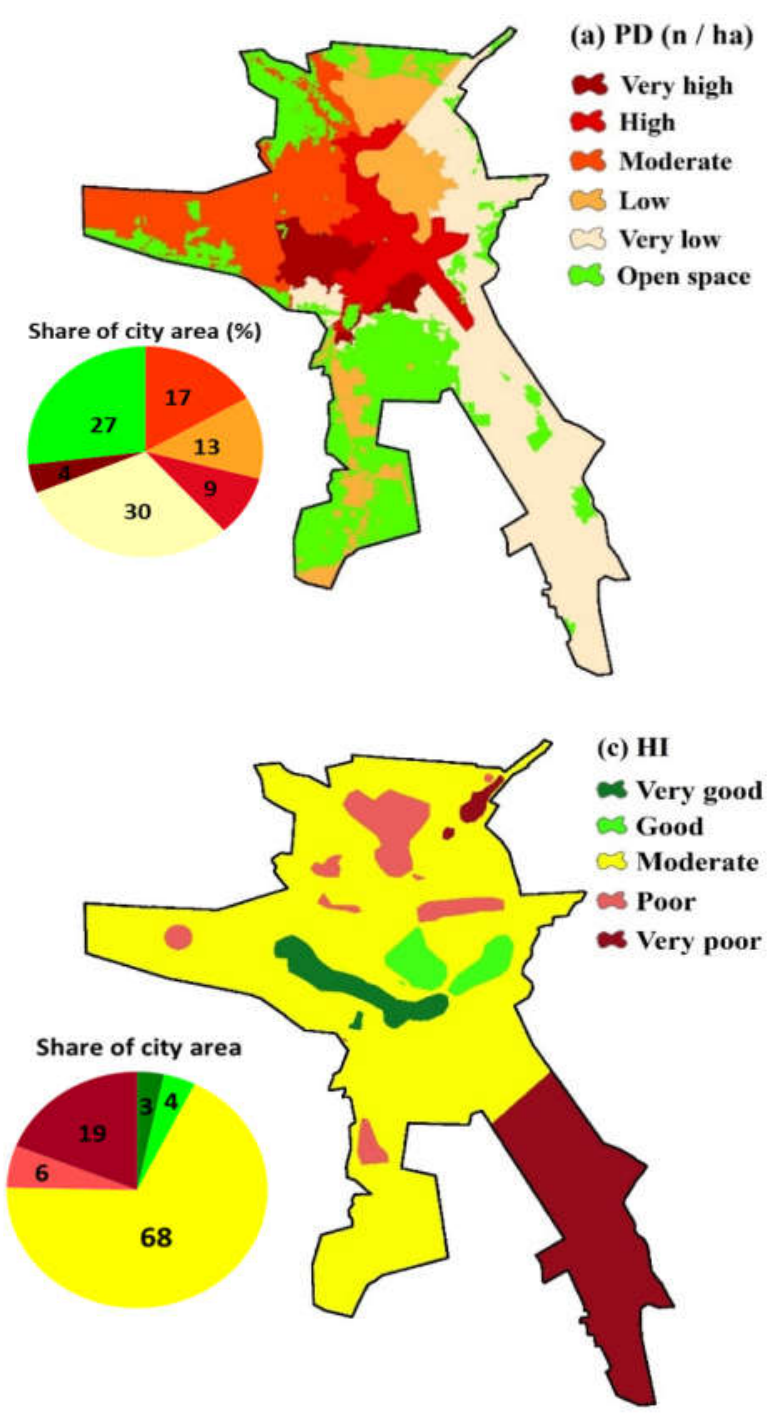

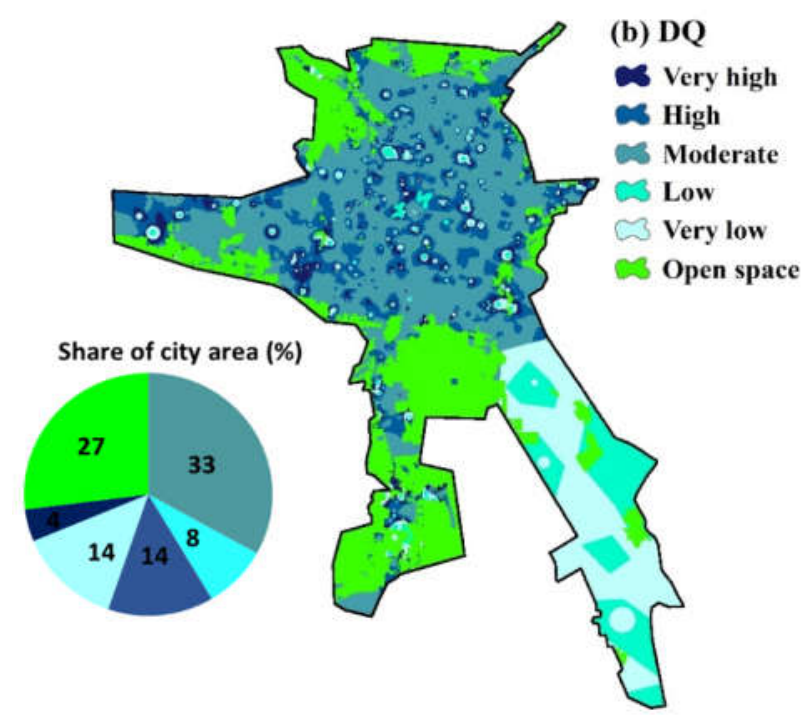

(d) DTCH (m)

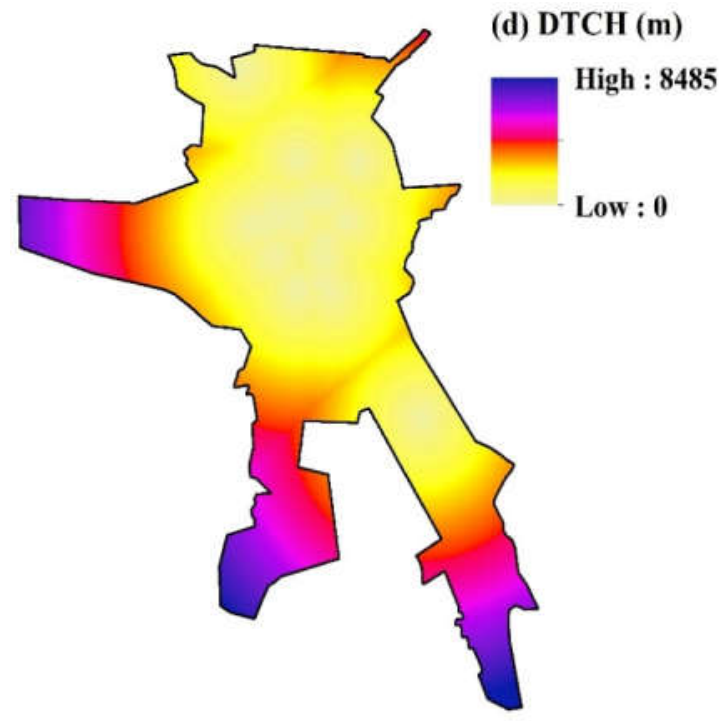



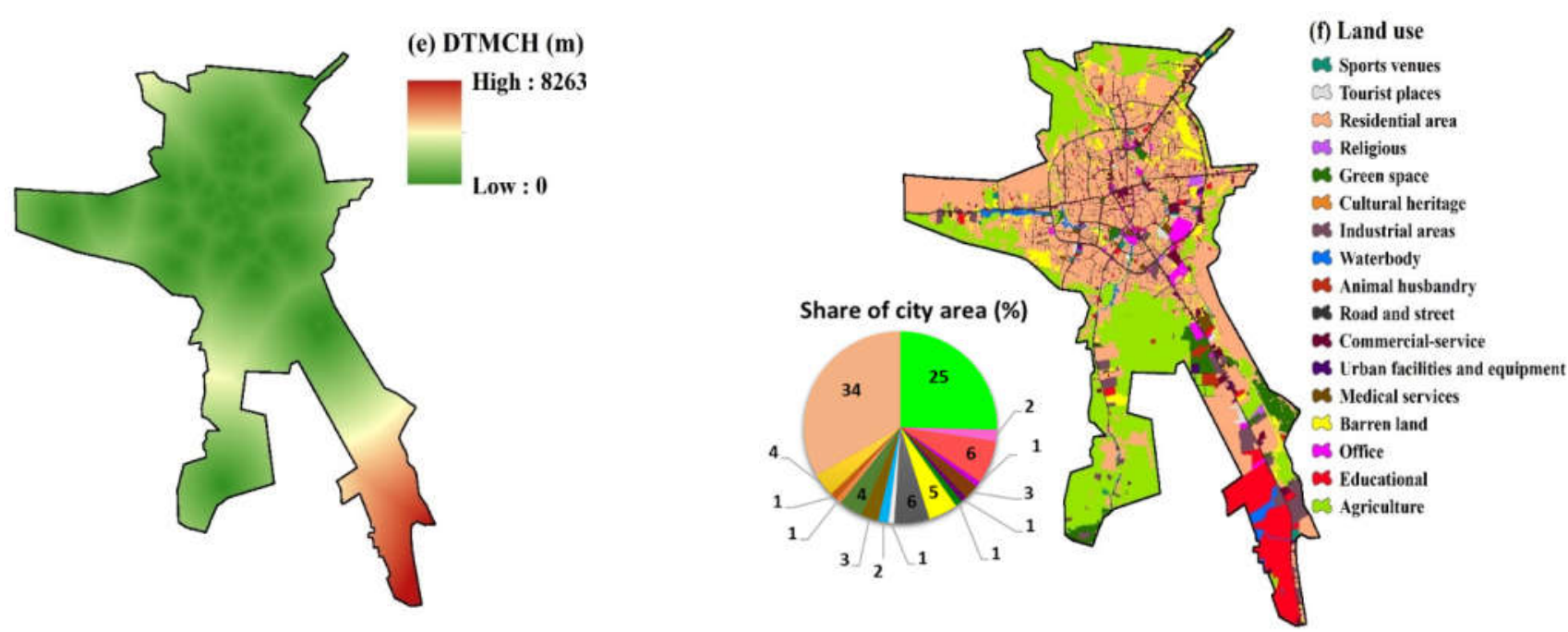

Figure 3. Vulnerability factors: a) population density (PD), b) dwelling quality (DQ), c) household income (HI), d) distance to cultural heritage (DTCH), e) distance to medical centers, and hospitals (DTMCH), and f) land use.

\subsection{Flood hazard evaluation}

In total, eleven flood conditioning parameters were used namely, elevation, slope angle, aspect, rainfall, distance to rivers (DTR), distance to streets (DTS), soil hydrology group (SHG), curve number (CN), distance to urban drainage (DTUD), urban drainage density (UDD), land use (Figure 4a to 4k). For producing the urban flood hazard map, each flooded and non-flooded point was assigned a value of 1 and 0 , respectively. The datasets were randomly chosen for training the machine learning models $(70 \%$ of the dataset) and validation (30\% of the dataset) by using the random tool in ArcGIS 10.7. The same training and validation dataset was used for all machine learning models.

\section{Elevation}

We applied a Digital Elevation Model (DEM) with a pixel size of $12 \times 12 \mathrm{~m}$ for data that were obtained from the Rasht City Authority. Elevation had a range between 14 and $255 \mathrm{~m}$ amsl (Figure 4a). Elevation influences the flood depth and generation of surface water flow. Regions at high elevations are less susceptible to flooding due to runoff flows at the base of the slope.

Slope angle

The slope angle map was created by using the Slope tool from the DEM layer in ArcGIS 10.7. The slope angle ranged from 0 to 8.4 degrees (Figure $4 \mathrm{~b}$ ). Increasing slope directly causes faster surface runoff and increases the discharge that influences flood hazard.

Aspect

In most flood studies, the slope aspect is introduced as the direction of the maximum slope of the area surface and this is one of the most important flood hazard indicators. It was created by using the Aspect tool from the DEM layer in ArcGIS 10.7. The aspect was 
categorized into nine categories: flat, north, northeast, east, southeast, south, southwest, west, and northwest (Figure 4c).

Rainfall

For preparing the rainfall layer, 15 meteorological stations (2000-2019) were taken from the Iranian Meteorological Organization (IRIMO). Annual rainfall of the region was created from the Inverse Distance Weighting (IDW) tool using ArcGIS 10.7 software which varies between 1227 and $1263 \mathrm{~mm}$ (Figure $4 \mathrm{~d}$ ).

\section{Distance to rivers (DTR)}

The banks of the Gohar and Zarjoub rivers are susceptible to flooding [39], thus Distance to rivers (DTR) has a pivotal role in the urban flood map in Rasht City. DTR had a range between 0 and $5449 \mathrm{~m}$ that was derived from the Euclidean tool using ArcGIS software (Figure 4e).

Distance to streets (DTS)

Streets and roads are impermeable and quickly generate runoff or inundate during floods, therefore regions near them are susceptible to flooding (Figure 4f; [36, 47]). The DTS map was created with the Euclidean distance tool in ArcGIS 10.7.

Soil hydrological group (SHG)

Soil hydrological groups show soil quality based on the smallest amount of water infiltration rate. Natural Resource Conservation Service has classified soils based upon the runoff potential of the soil into four Hydrologic Soil Groups (A, B, C, and D; [48]). Group D has the greatest runoff potential and group A has the smallest $[49,50]$. The SHG map was produced by the Water Company of Gilan Province. According to the SHG map, group D covers about $40 \%$ and group B $11 \%$ of the study area (Figure $4 \mathrm{~g}$ ).

\section{Curve number (CN)}

Curve number $(\mathrm{CN})$ is a dimensionless factor that is a function of hydrological conditions, land use, soil type, and previous soil moisture [51,22]. CN was between 0 and 100 with higher values showing higher runoff potential and lower showing lower runoff potential (Figure 4h; $[52,53]$ ). A CN map was created based on the land use and hydrologic soil group (HSG) maps using the ArcCN-runoff tool in ArcGIS 10.7.

Distance to urban drainage (DTUD)

During severe rainstorms, close areas to urban drainage systems are more prone to inundation and flooding. The DTUD was also produced with the Euclidean Distance tool in ArcGIS 10.7 (Figure 4i).

Urban drainage density (UDD)

Drainage density influences peak flows during rainfall [54]. Areas with high UDD are less flood-prone than areas with low UDD, thus this factor has an essential effect on 
flood hazards [55]. The UDD map was created using the line density tool in ArcGIS 10.7. (Figure 4j)

Land use

Land use has an essential role in infiltration, runoff rate, interception, and evaporation. Different land-use types directly affect runoff conditions [54,56]. The land use map in the area has seventeen different classes (Figure $4 \mathrm{k}$ ). Residential areas and streets are most susceptible to flood because in these regions soil infiltration capacity decreases, and runoff increases. 

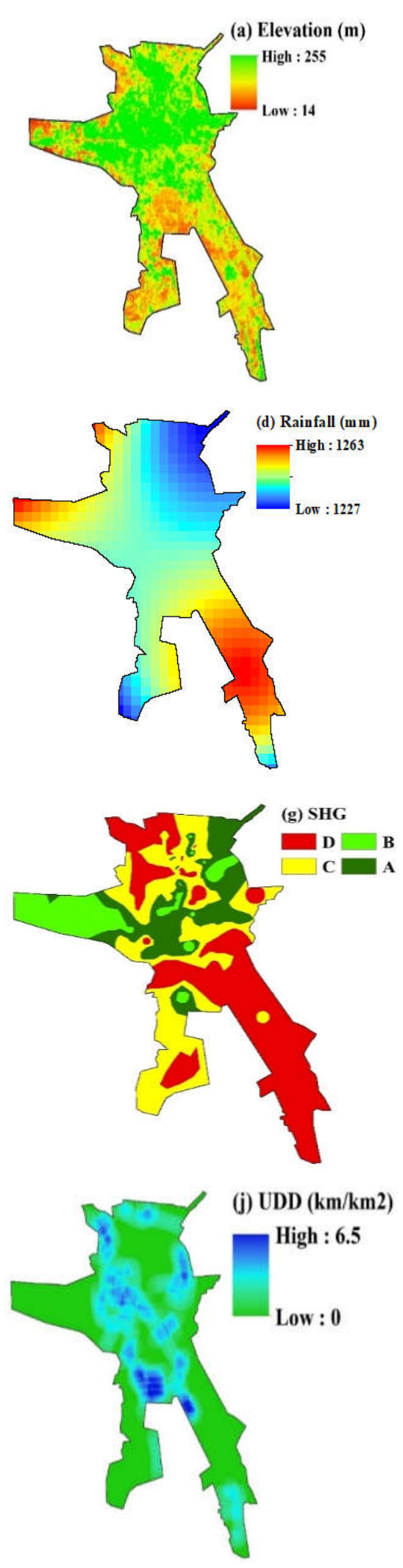

(b) Slope angle $\left({ }^{\circ}\right)$
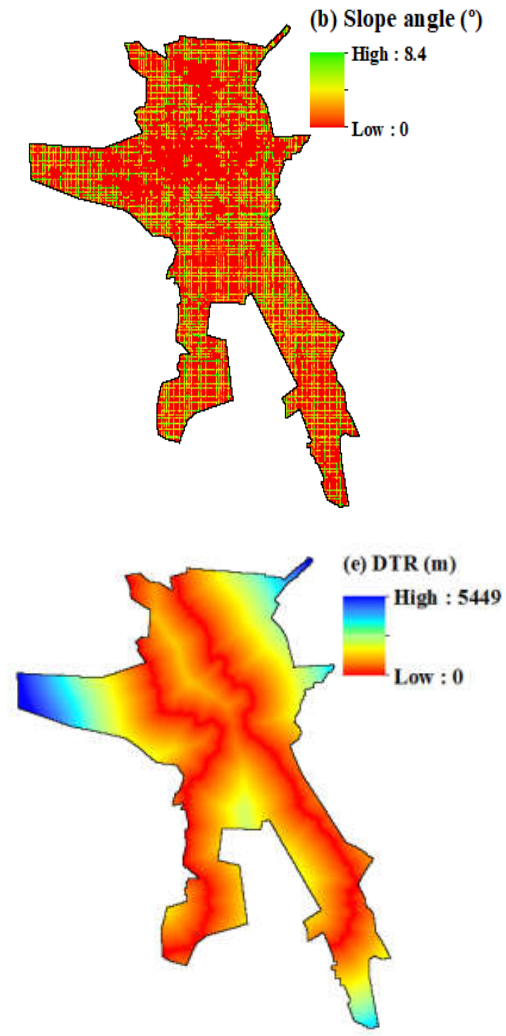

(h) $\mathrm{CN}$

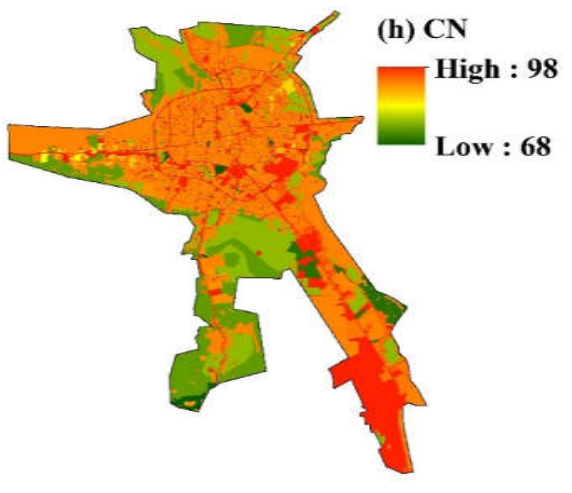

(k) Land use

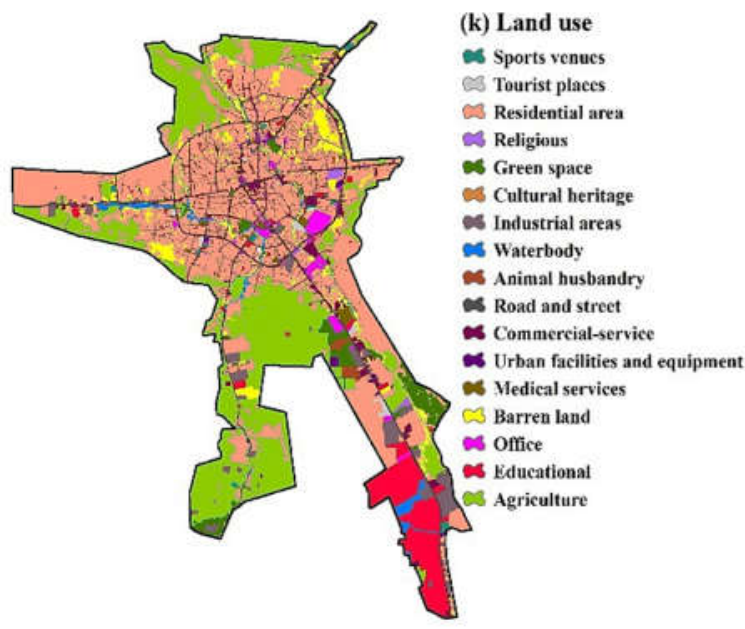

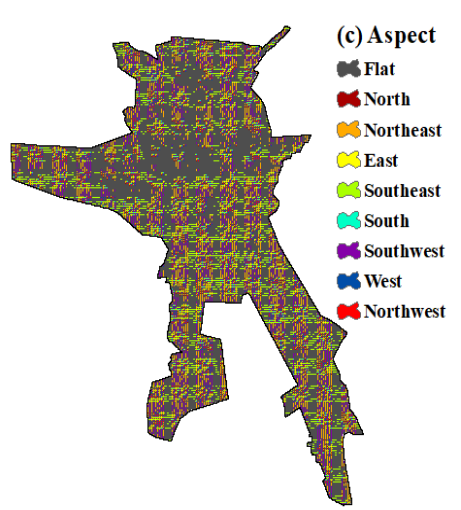
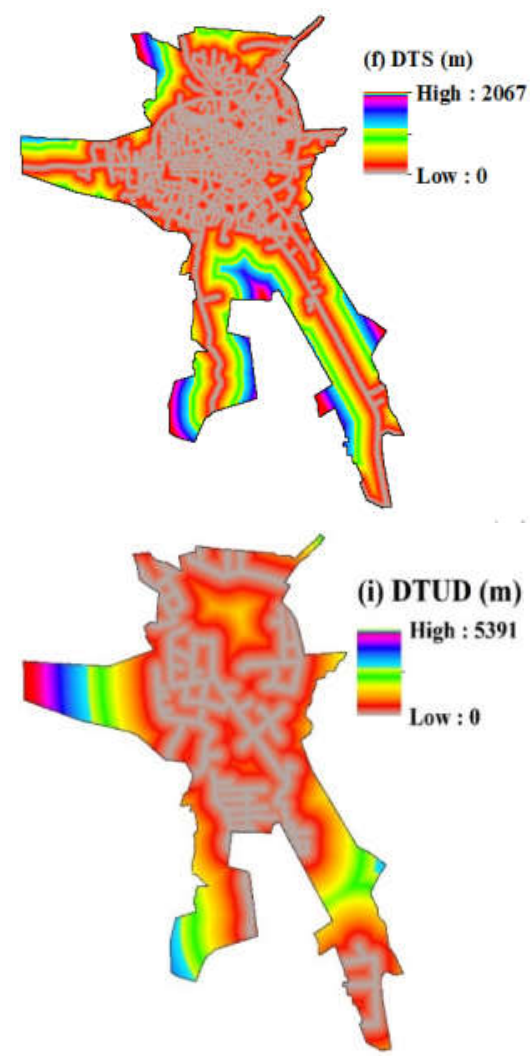

Figure 4. Flood hazard factors: a) elevation, b) slope angle, c) aspect, d) rainfall, e) distance to rivers, f) distance to streets, g) soil hydrological group, h) curve number, i) distance to urban drainages, j) urban drainage density, and k) land use. 


\subsection{Hazard modeling}

Classification and regression trees (CART), random forest (RF), boosted regression trees (BRT), multivariate adaptive regression splines (MARS), Multivariate discriminant analysis (MDA), and support vector machine (SVM) were applied to estimate the relationship among flooding and explanatory indicators and to create flood hazard maps. R software 4.0.4 and the SDM (Species Distribution Modeling) package [57] were used for performing the models. A summary description of every model is presented as follows:

- CART: Classification and regression trees (CART) as Decision tree (DT) models can be utilized for regression predictive modeling or classification [58, 59]. None of the different types of DT models, such as CART, Chi-squared Automatic Interaction Detection (CHAID), and Quick, Unbiased and Efficient Statistic Tree (QUEST) have previously been used for flood hazard mapping of the Rasht City. Equation 2 shows that the CART model will search between all values of all parameters:

$$
\arg \max \left[i\left(t_{p}\right)-P_{l} i\left(t_{l}\right)-P_{r} i\left(t_{r}\right)\right]
$$

Where $t_{p}, t_{l}$ and $t_{r}$ are parent, left and right nodes, $P_{l}$ and $P_{r}$ are probabilities of right and left nodes, and maximum homogeneity of child nodes is defined by impurity function $i(t)$. More information about the CART model can be found in Breiman et al. [58] and Lawrence et al. [29].

- RF: Random decision forests or Random forests (RF) is an ensemble learning method for regression and classification. The 'forest' created by the random forest model is trained through bootstrap aggregating. The building blocks of a random forest algorithm are decision trees and a decision support method. The decision tree has three components: decision nodes, leaf nodes, and root nodes. It divides a training dataset into branches that further segregate into other branches until a leaf node is attained. The leaf node cannot be segregated further. In the decision tree, the nodes show attributes that are applied to predict the outcome. A link to the leaves is provided with decision nodes [60, 32].

- BRT: BRT) is a machine learning algorithm merged with a statistical technique [34, 61]. BRT is frequently used with different decision trees for improving the performance of models [35]. More information about the BRT technique is described by Elith et al. [62] and Schapire [35].

- MARS: Multivariate adaptive regression spline (MARS) was introduced by Friedman [24]. This method is a non-parametric regression model that can be considered as an extension of linear models using automatic models interactions among nonlinear variables.

- MDA: The multivariate discriminant analysis (MDA) derives a linear combination of several variables that are best at differentiating between pre-determined independent categories. The procedure is performed by increasing the variance ratio for different categories [26]. 
- SVM: Support vector machine (SVM) is another machine learning model (supervised learning method) that is used for regression, classification, and outlier detection [36]. SVM draws a decision boundary which is a hyperplane between any two classes for classifying them or separating them into two categories (i.e., no flood or flood). The purpose is to specify an optimum dividing hyperplane to increase the margin among various categories of the training data and reduce the generalization error [63, 27].

\subsection{Performance evaluation}

Evaluation of models was done using a contingency table for binary forecasting (yes/no). According to previous studies [64], several metrics including accuracy, probability of detection (POD), false alarm ratio (FAR), and precision were used to evaluate and validate the model performance (Equations 3-6). Accuracy is a ratio of the number of correct predictions to the total number of input samples (which ranges between 0 to 1 ; [65]). The POD quantifies the probability to find a specific flaw, which is strongly connected to the subject of risk assessment and probabilistic analyses in the assessment of the integrity of components. POD is the proportion of the number of missing data to the total number of observed incidences and it ranges from 0 to 1 (perfect value of POD is equal to 1 ; [66]). The FAR is false alarms per total number of warnings or alarms in each study or situation (between 0 and 1, where 0 is the desired result; [67]). The Precision measures the number of hits to alarms per total number of warnings or alarms in each study. Precision is the closeness of measurements to each other, while accuracy is the closeness of measurements to a particular value.

$$
\begin{gathered}
\text { Accuracy }=\frac{(H+C N)}{(H+F A+M+C N)^{\prime}} \\
P O D=\frac{H}{(H+M)^{\prime}} \\
F A R=\frac{F A}{(H+F A)^{\prime}} \\
\text { Precision }=\frac{H}{(H+F A)^{\prime}}
\end{gathered}
$$

where $H$ indicates the number of hits, $F A$ shows the number of false alarms, $M$ is the number of misses, and $C N$ specifies the number of correct negatives in the confusion matrix [64]. In addition to the above statistics, the receiver-operator characteristic (ROC) and the area under the curve (AUC) were used to evaluate the performance of models [68, $65,27,69]$. The area under the curve (AUC-ROC) has been broadly applied for evaluating model accuracy and this method is the most popular assessment criterion.

\subsection{Urban flood risk assessment}

Risk is a function of hazard and vulnerability [37]. Vulnerability is linked to socioeconomic indicators, and hazard is to environmental indicators. Flood hazards may be low in an area, but socio-economic vulnerability may be high, or vice versa. Hence, vulnerability and hazard are jointly important for risk analysis. 
A flood risk map was produced for Rasht city based on vulnerability and flood hazard maps $[70,71]$ :

$$
\text { Risk }=\text { Hazard } \times \text { Vulnerability }
$$

\section{Results and discussion}

\subsection{Modeling results}

Model calibration was repeated until a suitable AUC was obtained (> 80\%) for which the flood hazard maps were produced. Accuracy, POD, FAR, and precision for the six models are shown in Tables 3 and 4 (for validation and training datasets). According to Table 3, AUC for CART, RF, BRT, MARS, MDA, and SVM models were respectively 0.947, 0.941, 0.921, 0.916, 0.889, and 0.781. Consequently, the SVM model indicated poor performance $($ accuracy $=0.768, \mathrm{POD}=0.759, \mathrm{FAR}=0.214$, and precision $=0.786$ ) compared to other models, because the SVM model only have the ability for separating non linear data. The main reason for the poor performance of the SVM model is that data are not linearly separable [72]. For the MDA model, poor performance is related to its need for normal distribution of data. The model is, as well, less capable of handling non-linear relations between output and input factors [73]. According to Table 4, the CART model indicates the best performance (accuracy $=0.892, \mathrm{POD}=0.867, \mathrm{FAR}=0.071$, and precision $=0.929$ ).

Table 3. Model performance using the training dataset.

\begin{tabular}{lcccccc}
\hline Criterion & CART & RF & BRT & MARS & MDA & SVM \\
\hline Accuracy & 0.985 & 0.931 & 0.901 & 0.869 & 0.854 & 0.831 \\
\hline POD & 0.985 & 0.924 & 0.906 & 0.871 & 0.833 & 0.794 \\
\hline FAR & 0.015 & 0.061 & 0.077 & 0.108 & 0.108 & 0.169 \\
\hline Precision & 0.985 & 0.938 & 0.923 & 0.892 & 0.892 & 0.831 \\
\hline
\end{tabular}

Table 4. Model performance using the validation dataset.

\begin{tabular}{lcccccc}
\hline Criterion & CART & RF & BRT & MARS & MDA & SVM \\
\hline Accuracy & 0.892 & 0.875 & 0.857 & 0.821 & 0.811 & 0.768 \\
\hline POD & 0.867 & 0.839 & 0.827 & 0.801 & 0.788 & 0.759 \\
\hline FAR & 0.071 & 0.071 & 0.111 & 0.133 & 0.143 & 0.214 \\
\hline Precision & 0.929 & 0.928 & 0.889 & 0.867 & 0.857 & 0.786 \\
\hline AUC & 0.947 & 0.941 & 0.921 & 0.916 & 0.889 & 0.781 \\
\hline
\end{tabular}




\subsection{Urban flood hazard map}

The flood hazard map was produced based on the result of the CART, RF, BRT, MARS, MDA, and SVM modeling (Figure 5). The equal interval classification method [74] was used to categorize the flood hazard map. This simplifies the model comparison. In other words, the interval classification method divides the categories equally with intervals of 0.2 (from 0 to 1 ). In each category, the number of records is different. When the distribution of data is rectangular, the equal interval classification method is sufficient [75]. Applying this approach, flood hazard maps were classified into five categories: very high, high, moderate, low, and very low (Figure 5). The findings of MDA and SVM algorithms were weak (Figure 5e-f; Table 5). CART, RF, BRT, and MARS algorithms had a similar distribution of flood hazard categories (Figure 5a-d; Table 5). Results indicated that mainly areas close to major rivers are most exposed to flooding and categorized as very high and high (about 38\% of the area). Similar finding was found by Yang et al. [76]. In this study area, land use and PD maps (Figure 3a and Figure 3f) show that residential regions with high and very high population density are located in regions with very high flood hazards (Figure 5). Therefore, efforts are needed to minimize future flood damage in these areas [76]. The map created By the CART, RF, BRT, and MARS models shows that low and very low flood hazards are representing regions in the west, northeast, and south of the study area (Figure 5a to $6 \mathrm{~d}$ ). According to the CART model map, very high and high hazard classes cover the greatest area, $41.8 \%$, and low and very low hazard classes cover only about $36 \%$ of the city. For the RF model map, very high and high hazard classes covered the smallest region, about $31 \%$, and the low and very low classes covered the greatest region $38.6 \%$ (Table 5).

Table 5. Areas for different flood hazard classes derived from the CART, RF, BRT, MARS, MDA, and SVM models

\begin{tabular}{cccccccccccccc}
\hline \multirow{2}{*}{ Flood hazard } & \multicolumn{2}{c}{ CART } & \multicolumn{2}{c}{ RF } & \multicolumn{2}{c}{ BRT } & \multicolumn{2}{c}{ MARS } & \multicolumn{2}{c}{ MDA } & \multicolumn{2}{c}{ SVM } \\
\cline { 2 - 14 } & $\mathbf{( \mathbf { k m } ^ { 2 } )}$ & $\mathbf{( \% )}$ & $\mathbf{( \mathbf { k m } ^ { 2 } )}$ & $\mathbf{( \% )}$ & $\mathbf{( \mathbf { k m } ^ { 2 } )}$ & $\mathbf{( \% )}$ & $\mathbf{( \mathbf { k m } ^ { 2 } )}$ & $\mathbf{( \% )}$ & $\mathbf{( \mathbf { k m } ^ { 2 } )}$ & $\mathbf{( \% )}$ & $\mathbf{( \mathbf { k m } ^ { 2 } )}$ & $\mathbf{( \% )}$ \\
\hline Very high & 20.6 & 21.7 & 14.1 & 14.8 & 21.7 & 22.8 & 24.9 & 26.3 & 32.2 & 33.9 & 1.6 & 1.7 \\
\hline High & 19.1 & 20.1 & 15.2 & 15.9 & 14.8 & 15.6 & 10.1 & 10.6 & 37.1 & 39.1 & 1.8 & 1.9 \\
\hline Moderate & 21.2 & 22.3 & 29.2 & 30.7 & 14.4 & 15.2 & 9.6 & 10.1 & 7.9 & 8.3 & 2.3 & 2.5 \\
\hline Low & 7.3 & 7.7 & 22.8 & 23.9 & 20.5 & 21.5 & 12.4 & 13.1 & 6.7 & 7.1 & 85.9 & 90.5 \\
\hline Very low & 26.8 & 28.2 & 13.7 & 14.7 & 23.6 & 24.9 & 37.9 & 39.9 & 11.1 & 11.6 & 3.2 & 3.4 \\
\hline Total & 95 & 100 & 95 & 100 & 95 & 100 & 95 & 100 & 95 & 100 & 95 & 100 \\
\hline
\end{tabular}



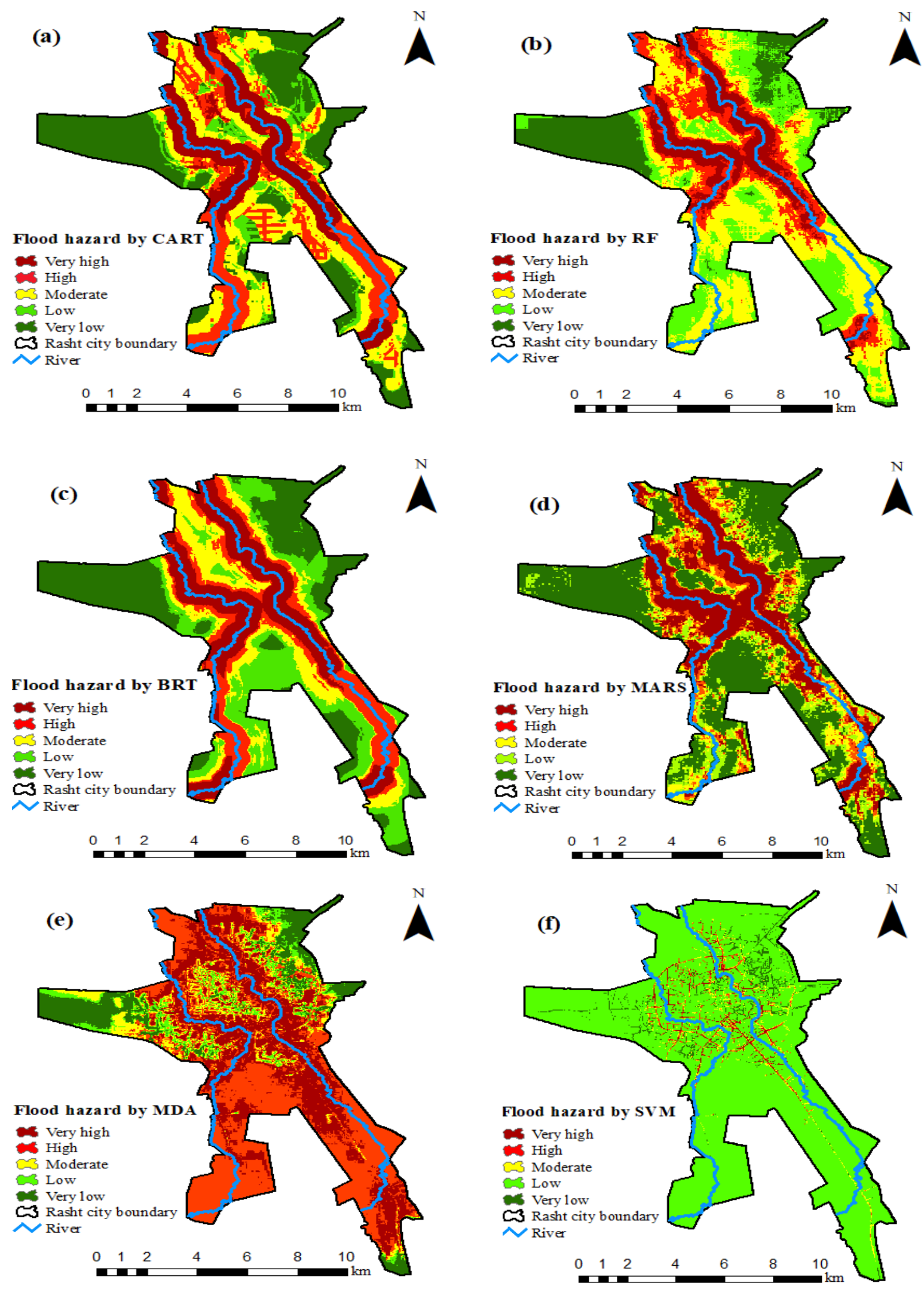

Figure 5. Flood hazard maps based on the (a) CART, (b) RF, (c) BRT, (d) MARS, (e) MDA, and (f) SVM models. 


\subsection{Importance of the flood hazard factors}

Selecting suitable conditioning factors is important in flood hazard modeling [77]. In the present study, the sensitivity of the factors was investigated using a Jackknife test, which is a fast and powerful method using partial-derivative calculations. Further details about the Jackknife test are described by Skinner and Rao [78]. The relative importance of the used flood hazard factors is shown in Figure 6. Distance to river (DTR) is estimated as the most influential factor, followed by urban drainage density (UDD), and distance to urban drainage (DTUD). Areas near rivers are prone to inundation during floodings. These results are consistent with those received from studies by Pham et al. [79] and Darabi et al. [80]. Other important factors are UDD and DTUD (Figure 6). Most roads and streets in Rasht, particularly in the north, southeast, and southwest regions of the study area do not contain suitable drainage systems (Figure $4 \mathrm{i}$ and $4 \mathrm{j}$ ), and have the highest flood hazard. The findings of this study are agreeing with the results of Falah et al. [81] and Ogden et al. [82]. Figureure 7 shows that the DTR had the highest importance across all models (38, 29.1, 33, 39, 35, and 33 for the CART, RF, BRT, MDA, MARS, and SVM model, respectively). The importance of UDD and DTUD in the CART method was about 23 and 12, respectively, all other factors were less than 5 (Figure 6a). In the RF and BRT models, the importance of all conditioning factors (except DTR and UDD) was less than 5 (Figure $6 \mathrm{~b}$ and $7 \mathrm{c}$ ). According to the MARS model, DTR, UDD, DTUD, and soil hydrological group (SHG) (with 35, 14, 9, and 6) were the most significant factors in the flood hazard map (Figure 6d). In the MDA model, the importance of the DTR, UDD, SHG, and rainfall was about 39, 14, 14,11, and 7, respectively, all other factors were less than 5 (Figure 6e). In the SVM model (Figure 6f), the most important factors were DTR and DTUD (values equal to 33 , and 7 , respectively).

(a) CART

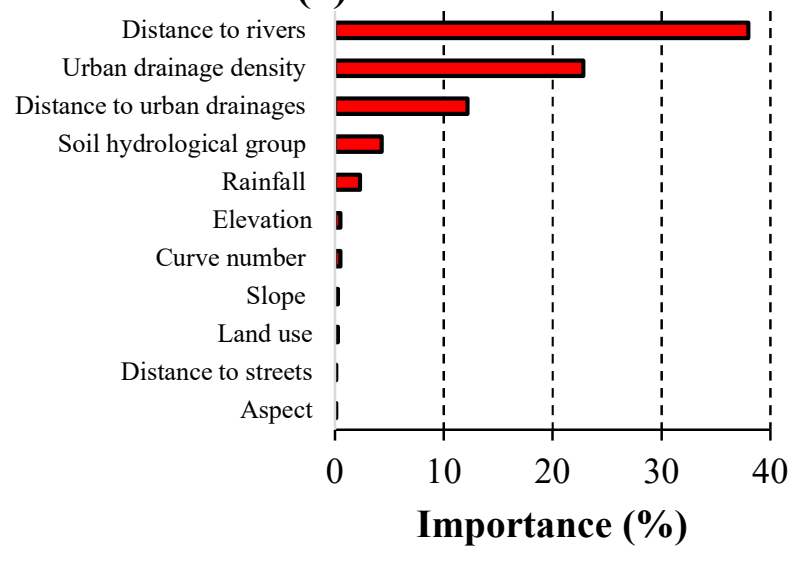

(b) $\mathbf{R F}$

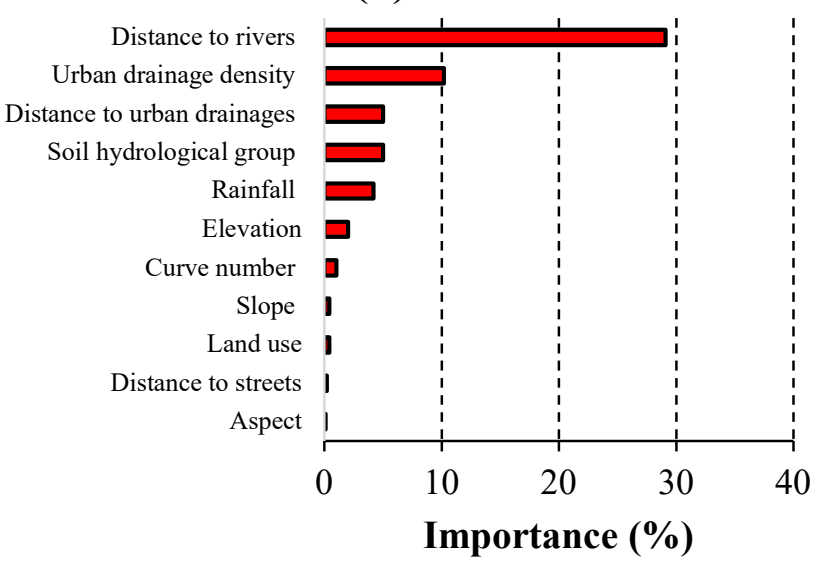




\section{(c) BRT}

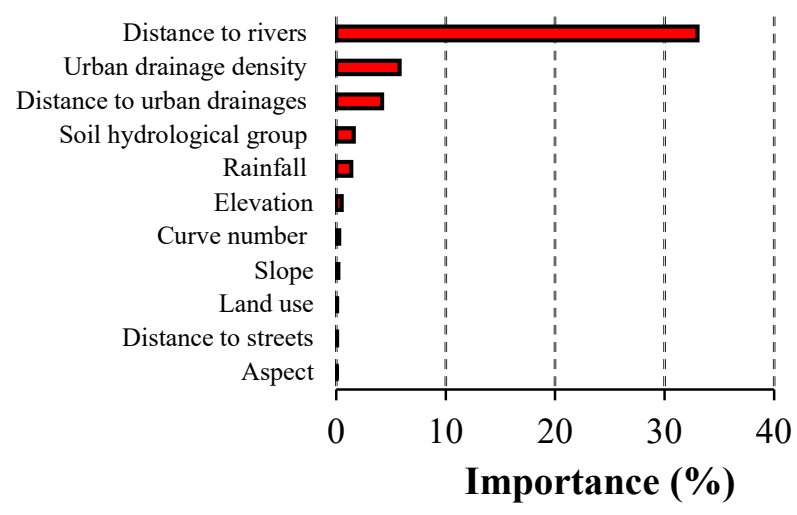

(e) MDA

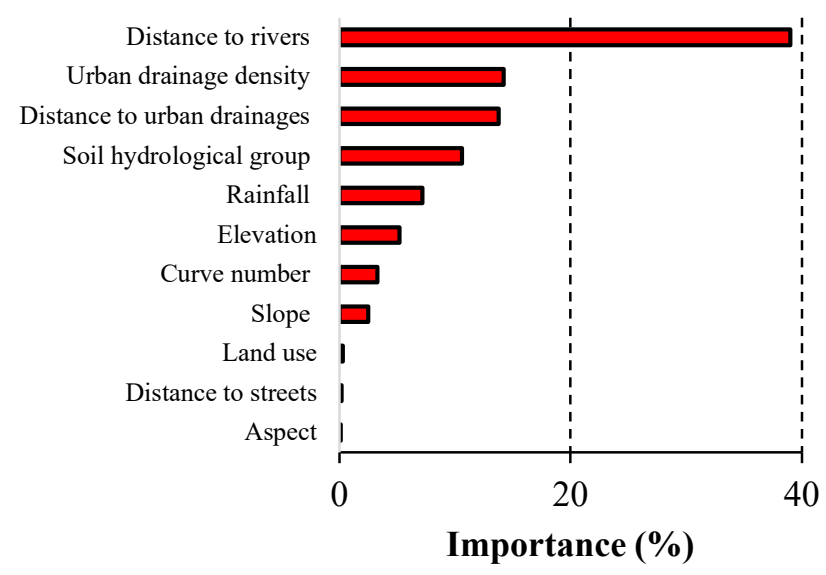

(d) MARS

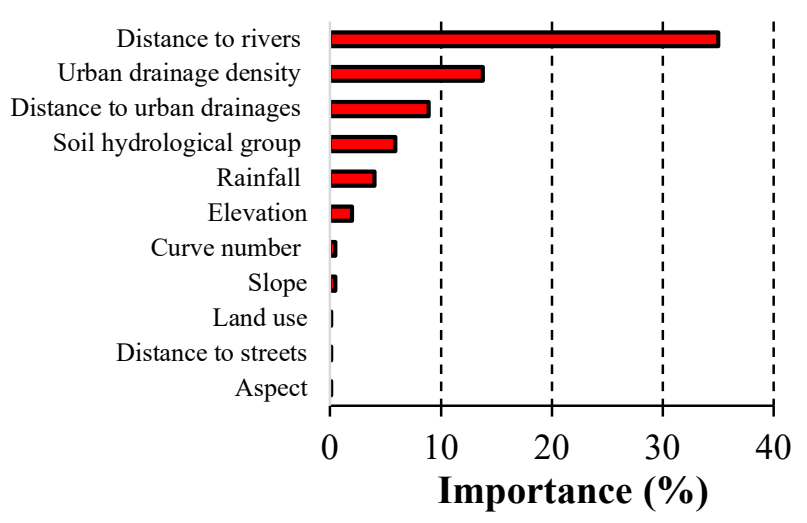

(f) SVM

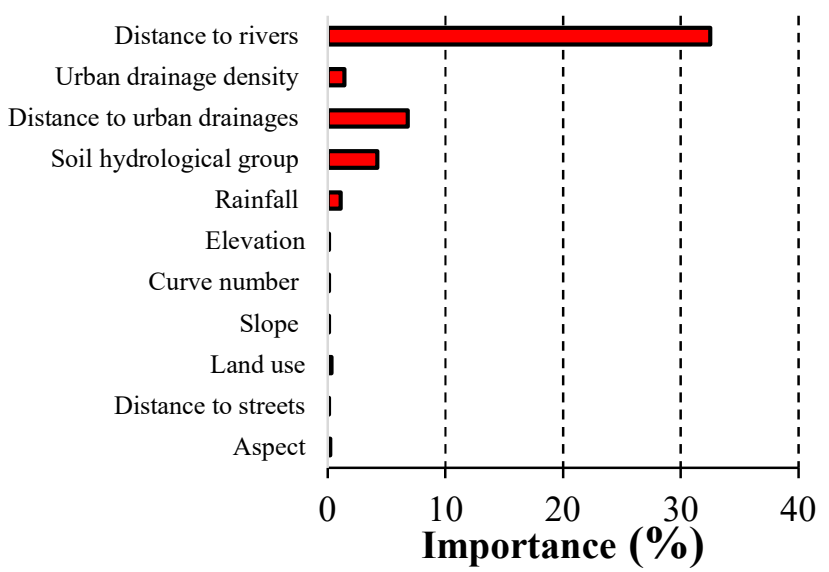

Figure 6. Importance of conditioning factors for urban flood hazard based on AUC.

\subsection{Importance of vulnerability indicators using the AHP method}

The AHP results indicated that among urban flood vulnerability parameters, population density (0.363), land use (0.279), and dwelling quality (0.158) were the most important, followed by household income (0.087), distance to cultural heritage (0.064), and distance to medical centers and hospitals (0.049). Table 6 shows the weights assigned to each parameter (based on the AHP method and expert knowledge). 
Table 6. Importance of the flood vulnerability indicators based on the AHP method.

\begin{tabular}{cc}
\hline Indicators & Weight \\
\hline Population density (PD) & 0.363 \\
\hline Land use & 0.279 \\
\hline Dwelling quality (DQ) & 0.158 \\
\hline Household income (HI) & 0.087 \\
\hline Distance to medical centers and hospitals (DTMCH) & 0.049 \\
\hline Total & 1.000 \\
\hline
\end{tabular}

\subsection{Urban flood vulnerability maps}

After computing the weights of layers based on the AHP approach, the pixel values of every layer were normalized using the proper membership functions (MF). Based on Samanlioglu et al. [83] and Azareh et al. [84], applying the continuous values according to the fuzzy method shows changes of factors in a more realistic way than other methods. As well, fuzzy methods can reduce uncertainty. Therefore, by analyzing the relationship between every layer and flood vulnerability, a suitable MF was used to standardize every layer between 0 and 1 using the fuzzy membership tool within ArcGIS 10.7 (Table 7).

Flood vulnerability map was conducted by using the weights obtained from the AHP method and fuzzy layers (Equation 1) within ArcGIS 10.7. The urban flood vulnerability map of Rasht was obtained with a pixel size of $12 \times 12 \mathrm{~m}$ (Figure 7). According to the Flood vulnerability map, the most vulnerable flooding areas were placed in the north and northeast of the city. Flood vulnerability map was classified into five classes for better visual interpretation (Figure 7): very low, low, moderate, high, and very high represent $27.3 \mathrm{~km}^{2}, 11.9 \mathrm{~km}^{2}, 18.8 \mathrm{~km}^{2}, 14.7 \mathrm{~km}^{2}$, and $22.3 \mathrm{~km}^{2}$ of the area, respectively (Table 8 ).

Table 7. Fuzzy membership function for different indicators.

\begin{tabular}{|c|c|}
\hline Indicators & Membership function \\
\hline Population density (PD) & Linear increasing \\
\hline Dwelling quality (DQ) & Linear decreasing \\
\hline Household income (HI) & Linear decreasing \\
\hline $\begin{array}{l}\text { Distance to cultural heritage } \\
\text { (DTCH) }\end{array}$ & Linear decreasing \\
\hline $\begin{array}{l}\text { Distance to medical centers and } \\
\text { hospitals (DTMCH) }\end{array}$ & Linear increasing \\
\hline Land use & $\begin{array}{l}\text { User-defined ( } 0 \text { for barren land, } 0.1 \text { for green space and water } \\
\text { body, } 0.3 \text { for sports venues, } 0.6 \text { for urban facilities and } \\
\text { equipment, cultural heritage, and tourist places, } 0.8 \text { for office, } \\
\text { Religious, Commercial-service and animal husbandry, } 0.9 \text { for } \\
\text { agriculture, roads and streets, educational, medical services, } \\
\text { and industrial area and } 1 \text { for residential area) }\end{array}$ \\
\hline
\end{tabular}


Table 8. Areas with different flood vulnerability categories.

\begin{tabular}{cc}
\hline Flood vulnerability & $\left.\mathbf{( k m}^{2}\right)$ \\
\hline Very high & 22.3 \\
\hline High & 14.7 \\
\hline Moderate & 18.8 \\
\hline Low & 11.9 \\
\hline Very low & 27.3 \\
\hline Total & 95 \\
\hline
\end{tabular}

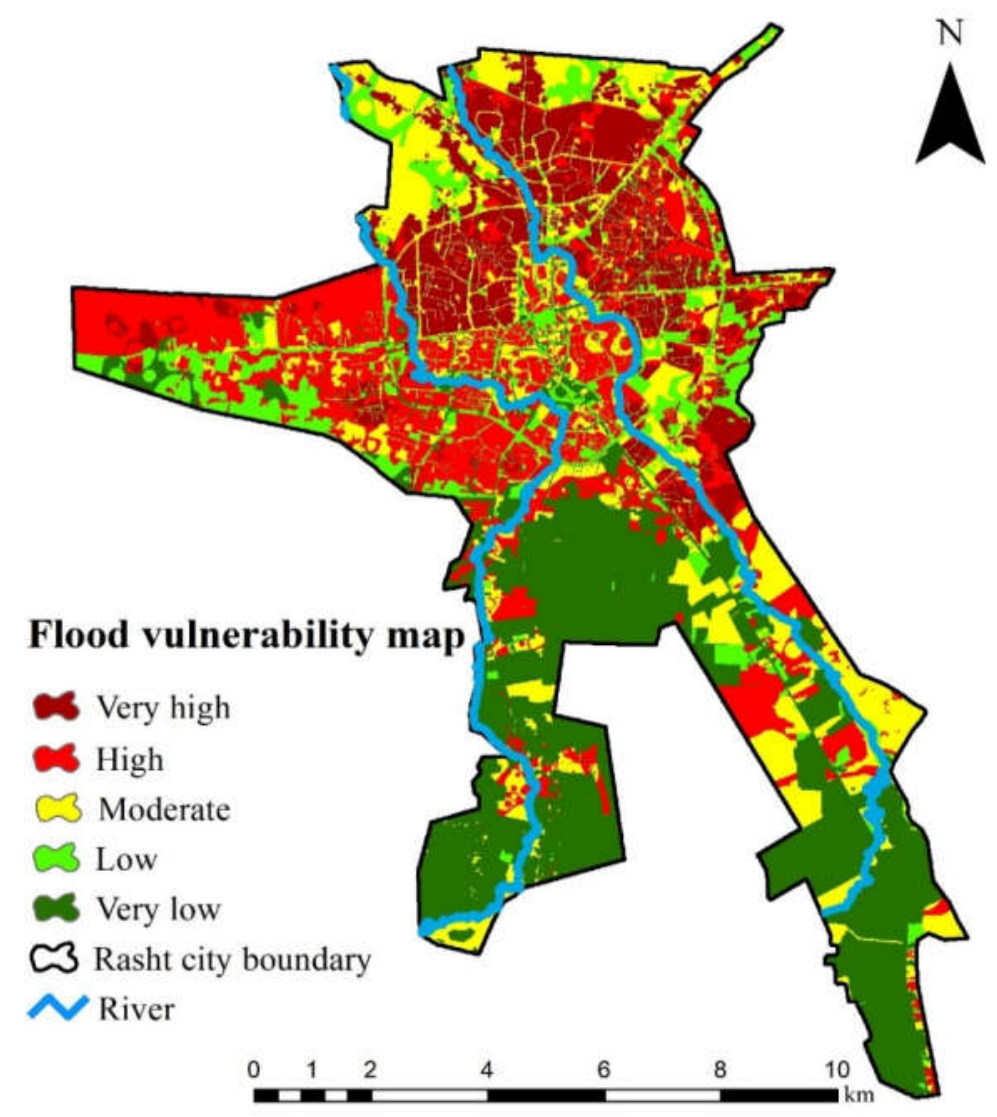

Figure 7. Flood vulnerability map for the Rasht City.

\subsection{Urban flood risk map}

The flood risk map for Rasht City was produced using the hazard and vulnerability maps. We used the vulnerability map produced based on the AHP technique and the hazard map produced through the best model (CART model). The flood risk map was divided into five classes by the equal interval method: very low, low, moderate, high, and very high (Figure 8 ) that cover $44.4 \mathrm{~km}^{2}, 22.7 \mathrm{~km}^{2}, 14.8 \mathrm{~km}^{2}, 8.8 \mathrm{~km}^{2}$, and $4.3 \mathrm{~km}^{2}$ of the city, respectively (Table 9). The north and southeast of the area are most exposed to flood risk and several parts in the west and central have a high flood risk (Figure 8). 
Table 9. Areas with different flood risk categories.

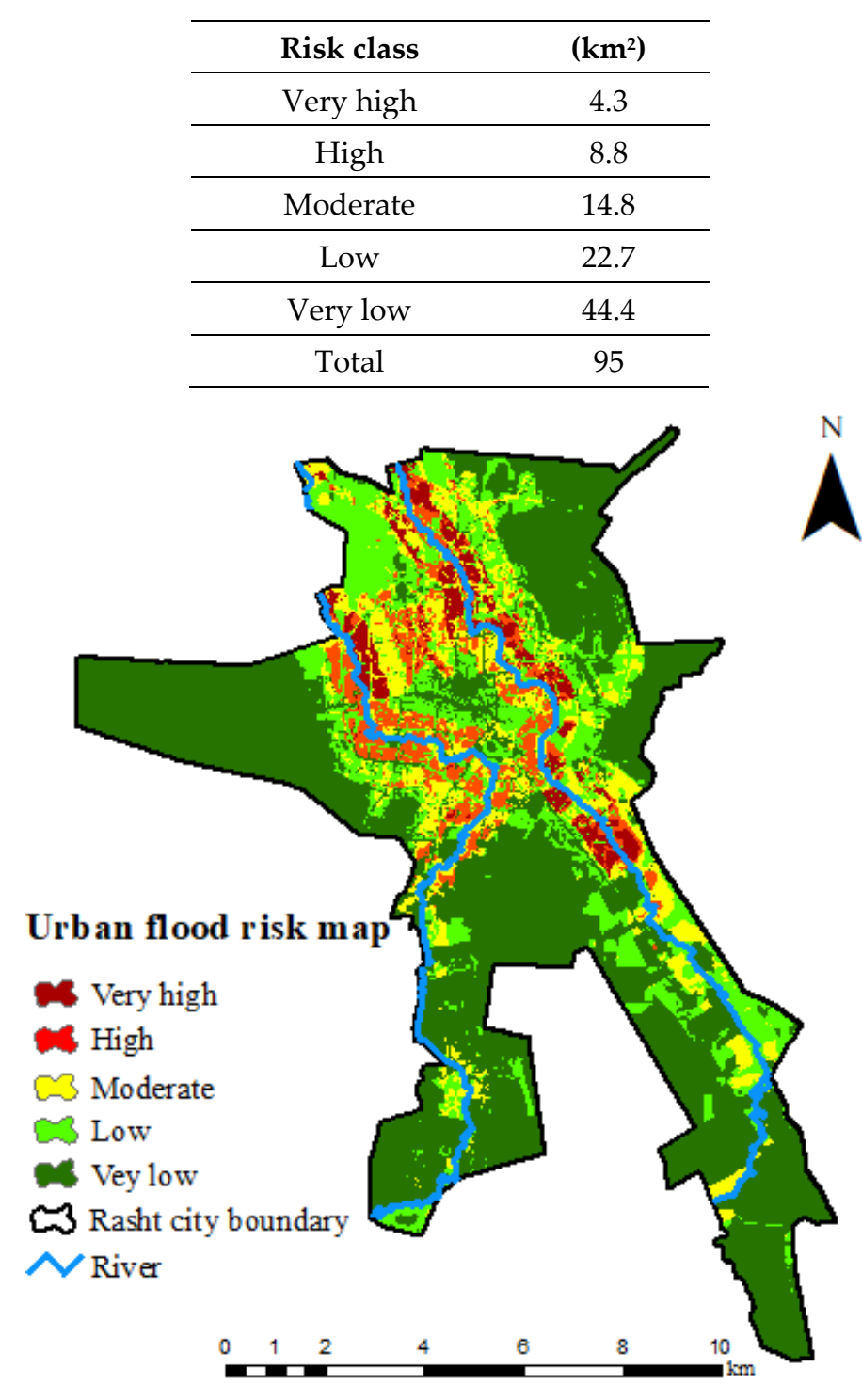

Figure 8. Flood risk map for Rasht City based on the CART (best hazard model) and AHP method.

\section{Conclusions}

We applied six machine learning techniques (CART, RF, BRT, MARS, MDA, and SVM) to create flood hazard maps of Rasht city in Iran. The MDA and SVM models had poor performances. The CART yielded an accurate and best map according to the results (accuracy $=0.892, \mathrm{POD}=0.867, \mathrm{FAR}=0.071$, and precision $=0.929$ ). Urban flood risk map was created using vulnerability and hazard maps (CART model). Distance to river, urban drainage density, and distance to urban were the most significant parameters that influenced flood hazard. Unplanned development of residential areas along rivers and lack of suitable drainage systems are the most influential proofs for inundation and flooding in Rasht city. Findings showed that machine learning methods are efficient in urban flood zoning. For urban flood vulnerability, based on the AHP method and expert knowledge, the weight for each factor was (population density $=0.363$, land use $=0.279$, dwelling quality $=0.158$, household income $=0.087$, distance to cultural heritage $=0.064$, and distance to medical centers and hospitals $=0.049$ ), and population density was the significant parameter in the urban flood vulnerability. 
The integrated technique outlined in the present study shows credible results can be created without complicated modeling and costly field surveys. The method presented is especially helpful in areas with little data, to describe and exhibit flood hazards. Vulnerability and hazard mapping can also serve as a first stage in advancing flood risk mitigation approaches and in allocating warning and forecasting systems. Appropriate drainage systems and maintenance of them are necessary for urban management and making plans to distribute urban residents in all regions is significant in decreasing flood risks. Due to human activities and climate change, the risk map changes over time, future studies on the current topic are therefore recommended.

\section{References}

[1] Alexander, M., Viavattene, C., Faulkner, H., Priest, S, "A GIS-based Flood Risk Assessment Tool: Supporting Flood Incident Management at the Local Scale," 2011.

[2] Feng , L.H; Lu, J, "The Practical Research on Flood Forecasting Based on Artificial Neural Networks," Expert Syst Appl, vol. 37, pp. 2974-2977, 2010.

[3] Klaus, S., Kreibich, H., Merz, B., Kuhlmann, B., Schröter, K, "Large-scale, seasonal flood risk analysis foagricultural crops in Germany," Environ Earth Sci, vol. 75, p. 1289, 2016.

[4] Modarres, R; Sarhadi, A; Burn, D.H, "Changes of extreme drought and flood events in Iran. Global and Planetary Change," vol. 144, pp. 67-81, 2016.

[5] Aminyavari, S; Saghafian, B; Sharifi, E, "Assessment of Precipitation Estimation from the NWP Models and Satellite Products for the Spring 2019 Severe Floods in Iran," Remote Sensing, vol. 11, no. 23, p. 2741, 2019.

[6] Hosseini, F.S; Khalighi, SH.S; Salajegheh, A; Moghaddamnia, A; Choubin, B, "Towards a Flood Vulnerability Assessment of Watershed Using Integration of Decision Making Trial and Evaluation Laboratory, Analytical Network Process, and Fuzzy Theories," Environmental Science and Pollution Research, vol. 28, p. 62487-62498, 2021.

[7] K. De Bruijn, "Resilience and flood risk management," Water Policy, vol. 6, p. 53-65, 2004.

[8] I. Overton, "Modelling floodplain inundation on a regulated river: Integrating GIS, remote sensing and hydrological models," River Res. Appl, vol. 21, no. 9, p. 991-1001, 2005.

[9] Wijayarathne, D.B; Coulibaly, P, "Identification of hydrological models for operational flood forecasting in St. John's, Newfoundland, Canada," Hydrol. Reg. Stud, vol. 27, 2020.

[10] J. J. Wiles and N. S. Levine, "A combined GIS and HEC model for the analysis of the effect of urbanization on flooding; the Swan Creek watershed, Ohio. Environ.," Eng. Geosci, vol. 8, no. 1, pp. 47-61, 2002.

[11] M. Gomes Miguez, B. Peres Battemarco, M. Martins De Sousa, O. Moura Rezende, V. A. Pires and G. Gusmaroli, "Urban Flood Simulation Using MODCEL-An Alternative Quasi-2D Conceptual Model," Water, vol. 9, no. 6, p. 445, 2017.

[12] Kauffeldt, A., Wetterhall, F., Pappenberger, F., Salamon, P., Thielen, J, "Technical review of large-scale hydrological models for implementation in operational flood forecasting schemes on continental level," Environ. Model. Softw, vol. 75, pp. 68-76, 2016. 
[13] Unduche,F., Tolossa, H., Senbeta, D., Zhu, E., "Evaluation of four hydrological models for operational flood forecasting in a Canadian Prairie watershed," Hydrol. Sci. J, vol. 63, no. 8, pp. 1133-1149., 2018.

[14] Mobini, S., P. Becker, R. Larsson, and R. Berndtsson, "Systemic inequity in urban flood exposure and damage compensation," Water, vol. 12, p. 3152, 2020.

[15] Nachappa, T.G., Piralilou, S.T., Gholamnia, K., Ghorbanzadeh, O., Rahmati, O. and Blaschke, T, "Flood susceptibility mapping with machine learning, multi-criteria decision analysis and ensemble using Dempster Shafer Theory," Journal of Hydrology, p. p.125275, 2020.

[16] Luu, C.; von Meding, J. A, "Flood Risk Assessment of Quang Nam, Vietnam Using Spatial Multicriteria Decision Analysis," Water, vol. 10, p. 461, 2018.

[17] Ouma, Y.O. and Tateishi, R, "Urban flood vulnerability and risk mapping using integrated multi-parametric AHP and GIS: methodological overview and case study assessment," Water, pp. 1515-1545, 2014.

[18] Danumah, J.H; Odai, S.N; Saley, B.M; Szarzynski, J; Thiel, M; Kwaku, A; Kouame, FK; Akpa, LY, "Flood risk assessment and mapping in Abidjan district using multi-criteria analysis (AHP) model and geoinformation techniques, (cote d'ivoire)," Geoenviron Disasters, vol. 10, no. 3, pp. 1-13, 2016.

[19] Tehrany, M.S., Kumar, L., Shabani, F, "A novel GIS-based ensemble technique for flood susceptibility mapping using evidential belief function and support vector machine: Brisbane, Australia," PeerJ, 2019.

[20] Chen, W., Li, Y., Xue, W., Shahabi, H., Li, S., Hong, H., Wang, X., Bian, H., Zhang, S., Pradhan, B., Ahmad, B. Bin, "Modeling flood susceptibility using data-driven approaches of naïve Bayes tree, alternating decision tree, and random forest methods," Sci. Total Environ, vol. 701, 2020.

[21] Berk R.A., Classification and Regression Trees (CART). In: Statistical Learning from a Regression Perspective, Springer, New York, NY.: Springer Series in Statistics, 2008.

[22] Zhao, G., Pang, B., Xu, Z., Yue, J., Tu, T, "Mapping flood susceptibility in mountainous areas on a national scale in China," Sci. Total Environ, vol. 615, p. 1133-1142, 2018.

[23] Shafizadeh-Moghadam, H., Valavi, R., Shahabi, H., Chapi, K., Shirzadi, A, "Novel forecasting approaches using combination of machine learning and statistical models for flood susceptibility mapping," J. Environ. Manage, vol. 217, pp. 1-11, 2018.

[24] Friedman, J. H., "Multivariate Adaptive Regression Splines," The Annals of Statistics, vol. 19, no. 1, pp. 1-67, 1991.

[25] Friedman, J. H., "Fast MARS," Stanford University Department of Statistics, Technical Report 110, 1993.

[26] Hair, J. F., Black, W. C., Babin, B. J., Anderson, R. E., \& Tatham, R. L, "Multivariate data analysis," vol. 5, no. 3, pp. 207-219, 1998.

[27] Tehrany, M.S., Pradhan, B., Mansor, S., Ahmad, N, "Flood susceptibility assessment using GIS-based support vector machine model with different kernel types," Catena, vol. 125, p. 91-101, 2015.

[28] Rahmati, O., Pourghasemi, H.R, "dentification of Critical Flood Prone Areas in Data-Scarce and Ungauged Regions: A Comparison of Three Data Mining Models," Water Resour. Manag, vol. 31, p. 1473-1487, 2017.

[29] R. Lawrence and A. Wright, "Rule-Based Classification Systems Using Classification and regression tree (CART) Analysis," Photogrammetric Engineering and Remote sensing, vol. 12, pp. 1137-1142, 2001.

[30] E. A. Timofeev, "Random minimal trees," Theory Probab. Appl, vol. 29, no. 1, pp. 134-141, 1984.

[31] Belgiu, M., Drăgu, L, "Random forest in remote sensing: A review of applications and future directions," ISPRS J. Photogramm. Remote Sens, vol. 114, p. 24-31, 2016. 
[32] Cutler, A., Cutler, D.R., Stevens, J.R, "Random Forests BT - Ensemble Machine Learning: Methods and Applications," Ensemble Mach. Learn, vol. 45, p. 157-175, 2012.

[33] Cutler, D.R., Edwards, T.C., Beard, K.H., Cutler, A., Hess, K.T., Gibson, J., Lawler, J.J, "Random forests for classification in ecology," Ecology, 2007.

[34] Yang, R.M., Zhang, G.L., Liu, F., Lu, Y.Y., Yang, Fan, Yang, Fei, Yang, M., Zhao, Y.G., Li, D.C, "Comparison of boosted regression tree and random forest models for mapping topsoil organic carbon concentration in an alpine ecosystem," Ecol. Indic, vol. 60, p. 870-878, 2016.

[35] Schapire, R. E, "The boosting approach to machine learning: an overview," Nonlinear Estimation and Classification, vol. 171, p. 149-171, 2003.

[36] Zhao, G., Pang, B., Xu, Z., Peng, D., Xu, L, "Assessment of urban flood susceptibility using semi-supervised machine learning model.," Sci. Total Environ, vol. 659, p. 940-949, 2019.

[37] Sharma, A., Tiwari, K.N., Bhadoria, P.B.S, "Effect of land use land cover change on soil erosion potential in an agricultural watershed," Environ. Monit. Assess, vol. 173, p. 789-801, 2011.

[38] National Statistics Center of Iran, "General Population and Housing Census and Agricultural Census," 2016. [Online]. Available: https://www.amar.org.ir/.

[39] Rasht Comprehensive Planning (RCP), "Final Report," Municipality of Rasht (Tarh-O-Kavosh Consulting Engineers, 2015.

[40] Hosseini, O, "Identifying the most important causes of floods in Rasht (case study of Rasht)," in 3rd National Conference of Flood Management and Engineering, 2015.

[41] Munyai, R.B., Musyoki, A., Nethengwe, N.S, "An assessment of flood vulnerability and adaptation: A case study of Hamutsha-Muungamunwe village, Makhado municipality," Jamba J. Disaster Risk Stud, vol. 11, 2019.

[42] T. L. Saaty, The Analytic Hierarchy Process: Planning, Priority setting, Resource allocation, New York: Mc GrawHill, 1980.

[43] A. Yalcin, "GIS-based landslide susceptibility mapping using analytical hierarchy process and bivariate statistics in Ardesen (Turkey): comparisons of results and confirmations," Catena, vol. 72, no. 1, pp. 1-12, 2008.

[44] Bidwai, D., Suman, S., Joy, S, "Flood Risk Assessment Using Analytical Hierarchy Process (AHP) and Machine Learning: A Comparison," Case Studies E Projects, Environment, Machine Learning, 2021.

[45] Brouwer, R., Akter, S., Brander, L. \& Haque, E.,, "Socioeconomic vulnerability and adaptation to environmental risk: A case study of climate change and flooding in Bangladesh," Risk Analysis, vol. 27, p. 313-326, 2007.

[46] Ward, P.S., Shively, G.E., "Disaster risk, social vulnerability, and economic development," Disasters, vol. 41, p. 324$351,2017$.

[47] Versini, P.A., Gaume, E., Andrieu, H, "Assessment of the susceptibility of roads to flooding based on geographical information - Test in a flash flood prone area (the Gard region, France)," Nat. Hazards Earth Syst. Sci, vol. 10, p. 793-803, 2010.

[48] National Engineering Handbook., Washington, DC.: Department of Agriculture, 2007, pp. U.S. , Part 630, chapter 7. .

[49] Gittleman, M., Farmer, C. J., Kremer, P., McPhearson, T, "Estimating stormwater runoff for community gardens in New York City," Urban Ecosystems, vol. 20, no. 1, pp. 129-139, 2017.

[50] USDA, S.C.S, "Urban hydrology for small watersheds. Technical release, 55. 2-6.," 1986. 
[51] Zhan, X., Huang, M.L, "ArcCN-Runoff: An ArcGIS tool for generating curve number and runoff maps," Environ. Model. Softw, vol. 19, p. 875-879, 2004.

[52] Darabi, H., Shahedi, K., Solaimani, K., Miryaghoubzadeh, M, "Prioritization of subwatersheds based on flooding conditions using hydrological model, multivariate analysis and remote sensing technique," Water. Environ. J, vol. 28, no. 3, pp. 382-392, 2014.

[53] Menberu, M. W., Haghighi, A. T., Ronkanen, A. K., Kværner, J., Kløve, B, "Runoff curve numbers for peatdominated watersheds," vol. 20, no. 4, p. 04014058, 2014.

[54] Komolafe, A. A., Herath, S., Avtar, R, "Methodology to Assess Potential Flood Damages in Urban Areas under the Influence of Climate Change," Natural Hazards Review, vol. 19, no. 2, p. 05018001, 2018.

[55] Mahmoud, S.H., Gan, T.Y, "Urbanization and climate change implications in flood risk management: Developing an efficient decision support system for flood susceptibility mapping," Sci. Total Environ, vol. 636, p. 152-167, 2018a.

[56] Yalcin, A., Reis, S., Aydinoglu, A.C., Yomralioglu, T, "A GIS-based comparative study of frequency ratio, analytical hierarchy process, bivariate statistics and logistics regression methods for landslide susceptibility mapping in Trabzon, NE Turkey," Catena, vol. 85, no. 3, pp. 274-287, 2011.

[57] Naimi, B., Araújo, M.B, "sdm: a reproducible and extensible R platform for species distribution modelling," Ecography, vol. 39, p. 368-375, 2016.

[58] L. Breiman, J. Friedman, R. Olshen and C. Stone, Classification and Regression Trees (Wadsworth Statistics/Probability), New York: Chapman and Hall, 1984.

[59] J. Brownlee, Master Machine Learning Algorithms, San Francisco: Machine Learning Mastery, 2016.

[60] Breiman, L, "Random forests," Mach. Learn, vol. 45, p. 5-32, 2001.

[61] Aertsen, W., Kint, V., de Vos, B., Deckers, J., van Orshoven, J., Muys, B, "Predicting forest site productivity in temperate lowland from forest floor, soil and litterfall characteristics using boosted regression trees," Plant Soil, vol. 354, p. 157-172, 2012.

[62] Elith, J., Leathwick, J.R., Hastie, T, "A working guide to boosted regression trees," J. Anim. Ecol, 2008.

[63] Abe, S, "Multiclass Support Vector Machines," pp. 113-161, 2010.

[64] Sokolova, M., Japkowicz, N., Szpakowicz, S, "Beyond Accuracy, F-Score and ROC: A Family of Discriminant Measures for Performance Evaluation," AAAI Workshop - Technical Report, p. 1015-1021, 2006.

[65] Mosavi, A., Ozturk, P., Chau, K.W, "Flood prediction using machine learning models: Literature review," Water (Switzerland), 2018.

[66] Wilks, D. S, "“Cluster Analysis," in Statistical Methods," in the Atmospheric Sciences, p. 603-616, 2011.

[67] Levine, R. A. and Wilks, D. S., "Statistical Methods in the Atmospheric Sciences," J. Am. Stat. Assoc, vol. 95, p. 344, 2000.

[68] P. C. G. a. C. A. Frattini, "Techniques for evaluating the performance of landslide susceptibility models," Eng. Geol, vol. 111, pp. 62-72, 2010.

[69] Yesilnacar, E.K, "The application of computational intelligence to landslide susceptibility mapping in Turkey," University of Melbourne, Department, 2005, p. 200.

[70] Zêzere, J.L., Garcia, R.A.C., Oliveira, S.C., Reis, E, "Probabilistic landslide risk analysis considering direct costs in the area north of Lisbon (Portugal)," Geomorphology, vol. 94, p. 467-495, 2008. 
[71] Chung, C.J.F.C.J.F., Fabbri, A.G, "Systematic Procedures of Landslide Hazard Mapping for Risk Assessment Using Spatial Prediction Models," Landslide Hazard Risk, pp. 139-174, 2012.

[72] Batuwita, R. and Palade, V, "Class Imbalance Learning Methods for Support Vector Machines," In Imbalanced Learning , 2013.

[73] Xie, C., Luo, C., \& Yu, X, "Financial distress prediction based on SVM and MDA methods: the case of Chinese listed companies," Quality \& Quantity, vol. 45, no. 3, pp. 671-686, 2011.

[74] T. Judith , Principles of Map Design, New York: The Guilford Press, 2010, p. 167.

[75] T. Slocum, Thematic Cartography and Geovisualization, New York: Pearson Prentice Hall: Upper Saddle River, 2009 , p. 60.

[76] Yang, W., Xu, K., Lian, J., Ma, C. and Bin, L, "Integrated flood vulnerability assessment approach based on TOPSIS and Shannon entropy methods," Ecological Indicators, vol. 89, pp. 269-280, 2018.

[77] Kourgialas, N.N., Karatzas, G.P, "Flood management and a GIS modeling method to assess flood hazard areas - a case study," Hydrol. Sci. J, vol. 56, no. 2, p. 212-225, 2012.

[78] Skinner, C.J. Rao, J.N.K., "Estimation in dual frame survey with complex design,," Journal of the American Statistical Association, vol. 91, pp. 349-356, 1996.

[79] Pham, B.T., Avand, M., Janizadeh, S., Phong, T.V., Al-Ansari, N., Ho, L.S., Das, S., Le, H.V., Amini, A., Bozchaloei, S.K., Jafari, F., Prakash, I., "GIS Based Hybrid Computational Approaches for Flash Flood Susceptibility Assessment," Water, vol. 12, p. 683, 2020.

[80] Darabi, H., Haghighi, A.T., Mohamadi, M.A., Rashidpour, M., Ziegler, A.D., Hekmatzadeh, A.A., Kløve, B, "Urban flood risk mapping using data-driven geospatial techniques for a flood-prone case area in Iran," Hydrol. Res, vol. 51, p. 127-142, 2020.

[81] Falah, F., Rahmati, O., Rostami, M., Ahmadisharaf, E., Daliakopoulos, I.N., Pourghasemi, H.R, "Artificial Neural Networks for Flood Susceptibility Mapping in Data-Scarce Urban Areas," Spat. Model. GIS R Earth Environ. Sci, p. 323-336, 2019.

[82] Ogden, F.L., Pradhan, N.R., Downer, C.W., Zahner, J.A.,, "Relative importance of impervious area, drainage density, width function, and subsurface storm drainage on flood runoff from an urbanized catchment," water resources, vol. 47, pp. 1-12, 2011.

[83] F. \&. A. Z. Samanlioglu, "Fuzzy ANP-based PROMETHEE II approach for evaluation of machine tool alternatives," Journal of Intelligent Fuzzy Systems, vol. 30, p. 2223-2235, 2016.

[84] Azareh, A., Rafiei Sardooi, E., Choubin, B., Barkhori, S., Shahdadi, A., Adamowski, J., Shamshirband, S, "Incorporating multi-criteria decision-making and fuzzy-value functions for flood susceptibility assessment," Geocarto Int, 2019. 